\title{
The Relationship between Transformational Leadership and Organizational Performance: The Case of Government Sector in UAE
}

\author{
Nayef Alateibi, Ahmed Hamoud Al-Shibami, Ali Ameen, Amiya Bhaumik, Ibrahim Alrajawy
}

\begin{abstract}
This study employs structural equations modeling via PLS to analyze the 392 valid questionnaires in order to assess the proposed model that is based on the transformational leadership characteristics to identify its effect on the performance of organizations in the government sector in the United Arab Emirates. The main independent constructs in the model are idealized influence, inspirational motivation, intellectual stimulation, and individualized consideration. The dependent construct is organizational performance as a second-order construct to learning \& growth, and internal process. The study will describe relations among the various constructs. Our work has improved our insight in the importance of transformational leadership. Results indicated that all four independent variables significantly predicted performance with a various percentage. The proposed model explained $46.5 \%$ of the variance in performance.
\end{abstract}

Keywords: Transformational leadership; organizational performance; $U A E$.

\section{INTRODUCTION}

L eadership, within the field of academia, appear in a variety of contexts and settings. Ultimately, the concept has been used a large number of times by scholars and practitioners alike in numerous speeches and writings. Despite its wide usage as well as the availability of conceptual suggestions and propositions even theoretically, researchers have still not come to a consensus over its agreed meaning in literature. Varied perspectives exist on whether leadership is a role, function, attribute, or any combination of any of these. Underlying assumptions of leadership models have built on specific leadership behaviors to be used in specific environments of situations.

Transformational leadership and their overarching role to induce success in the face of change and environmental turbulence by enhancing and redefining organizational

Revised Manuscript Received on September 25, 2019

Nayef Alateibi, Faculty of Business and Accountancy, Lincoln University College, Selangor, Malaysia

Ahmed Hamoud Al-Shibami, Faculty of Business and Accountancy, Lincoln University College, Selangor, Malaysia

Ali Ameen, Faculty of Business and Accountancy, Lincoln University College, Selangor, Malaysia

Amiya Bhaumik, Faculty of Business and Accountancy, Lincoln University College, Selangor, Malaysia

Ibrahim Alrajawy, Faculty of Business and Accountancy, Lincoln University College, Selangor, Malaysia performance and business processes is imperative to the present investigation. Avolio, Bass, \& Jung (1999) [1] agree that transformational leadership has become a prevalent method of determining the impact leaders have on organizational performance and underlying business processes. Avolio et al. (1999) [1] stressed that transformational leadership has over the years showed a close association with the determinants of organizational performance.

Due to the current environments that is known to be very competitive and innovative, the link between organizational performance and transformational leadership is never clearer, where competitive advantage is only obtained through innovativeness that enables organizations to improve their outcomes. In such situation, managers must focus in motivating their employees to be part of the innovation processes, and continuously gaining new knowledge that will allow companies to introduce new products into the market [2-6]. In this point, transformational leadership and human resource practices are seen as a trigger of competence and innovation by recent literature [7]. Further, Heffernan, Harney, Cafferkey, \& Dundon (2016) [8] suggested that there is a need for research regarding the variables that mediate between human resource practices and overall performance.

In the current context, the public sector of the UAE has changed in scope over the last few years and continues to implement changes in a manner that is much is similar to the private sector in contemporary times. Turkyilmaz, Akman, Özkan, \& Pastuszak (2011) [9] mention that the UAE public sector seeks to offer customer-centric services and is experiencing an ongoing change in various sectors. As a result of this pressure to change, the public-sector organizations have shown an increased interest in adopting transformational leadership that will help achieve results in this regard.

\section{LITERATURE REVIEW}

\section{A. Organizational Performance (OP)}

Organizational performance is among the most important variables in the management research and arguably the most important indicator in determining the overall organizational performance. It is the measure of standard or prescribed 
The Relationship between Transformational Leadership and Organizational Performance: The Case of Government Sector in UAE

indicators of effectiveness, efficiency, and environmental responsibility such as cycle time, productivity, waste reduction, and regulatory compliance. Organizational performance is the ultimate dependent variable of interest by researchers whose concern on management study. This broad construct is essential in permitting researchers and managers to evaluate organizations over time and compare them to rivals. In short, organizational performance is the most important criterion in evaluating organizations, their actions, and environments. This importance is reflected in the pervasive use of organizational performance as a dependent variable in previous research $[3,4]$. This study will examine performance as a second-order construct of two factors namely, learning \& growth, and internal process. Leaning \& growth refers to how staff are trained and educated, gain and capture knowledge. Kaplan \& Norton (1996) [10] noted that learning and growth come from three principle sources: people, systems and organizational procedures. As for internal process, it refers to what processes must an organization excels at, to achieve its public service objectives, which will have the greatest effect on public satisfaction and its financial objectives. The critical processes enable the department to deliver the expectations of the public and satisfy the leaders of the country expectations of high outcomes [10].

\section{B. Transformational Leadership (TL)}

Transformational leadership has been widely accepted as the ideal leadership style in contemporary organizations. This form of leadership has gained recognition due to the recognizable impact of transformational leadership and its ability to achieve organizational outcomes such as employee satisfaction and organizational performance [11]. It is widely accepted that transformational leadership has the peculiar ability to instigate higher order need [12, 13]. The study added that transformational leadership has the ability to motivate employees and generating positive emotions, the creation of an inspirational vision for the vision and directing followers towards achieving these objectives. Drawing on

\section{B. Development of Instrument}

The development of an instrument for this study included a 30-item questionnaire, and based on the performance literature, the study applied a multi-item Likert scale. Constructs were measured using a Likert scale which recommended in the previous studies [14-16] with 5 being 'Strongly Agree' and 1 being 'Strongly Disagree'. Given the fact that the respondents were Arabic-speakers, it is required to have the questionnaires translated from English to Arabic proposed dimensions of transformational leadership by several authors derived four dimensions of transformational leadership which are fundamental to the present study: Idealized Influence, Inspirational Motivation, Intellectual Stimulation and Individualized Consideration [11-13]. Consequently, the following hypotheses are proposed:

H1: Idealized influence has a positive effect on organizational performance.

$\mathrm{H} 2$ : Inspirational motivation has a positive effect on organizational performance.

H3: Intellectual stimulation has a positive effect on organizational performance.

H4 Individualized consideration has a positive effect on organizational performance.

\section{RESEARCH METHOD}

\section{A. Overview of the Proposed Research Model}

The relationships between constructs hypothesized in the conceptual framework have been adapted from the relevant literature in the subject matter. Fig 1 shows the proposed model that contains transformational leadership (idealized influence, inspirational motivation, intellectual stimulation, and individualized consideration) to predict organizational performance in terms of learning \& growth and internal process. The proposed model assesses the relationship between the aforementioned constructs among government employees in the United Arab Emirates. The proposed conceptual framework has four hypotheses to be tested.

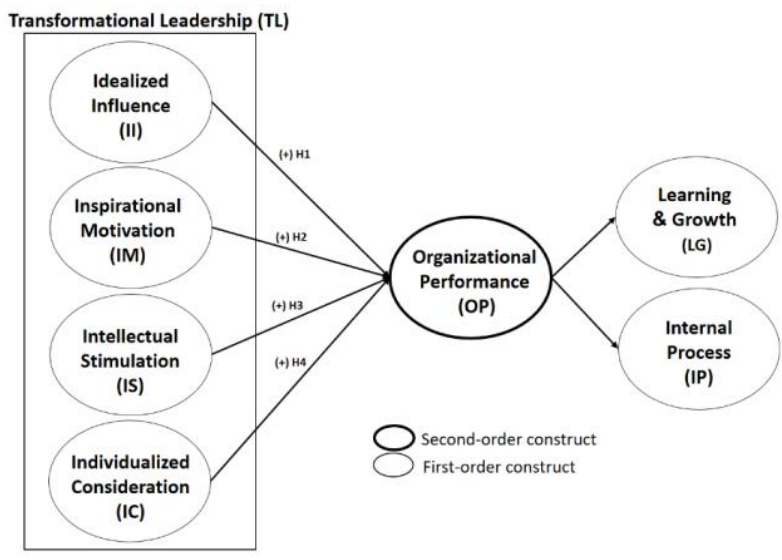

Fig. 1: PLS algorithm results

in a precise way. Thus a back translation was applied, which is a procedure widely used in a cross-cultural survey. Previous studies were used to get a validated to measure the variables in this study as shown in Appendix A.

\section{Data Collection}

The data was collected by delivering a self-administered questionnaires 'in-person' from April 2017 until August 2017 to government employees. The number of the distributed questionnaires was 700 , 
and the number of the returned sets is 423 of which 392 responses were considered suitable for the analysis. According to Tabachnick \& Fidell (2012) [17] and Krejcie \& Morgan (1970) [18], the sample size was seen as sufficient. Compared to the relevant literature the $60.43 \%$ response rate of this study is considered very good. The number of the deleted questionnaires was 31 including a 21 missing data cases of more than $15 \%$ of the questions, and 3 cases as outliers, and 7 cases that have a straight lining.

\section{Data Analysis and Results}

Partial Least Squares (PLS) Structural Equation Modeling-Variance Based (SEM-VB) was utilized to examine the research model in this research, by using the SmartPLS 3.0 software [19]. A two-stage analytical method [20, 21] comprising (i) measurement model assessment (validity and reliability) and (ii) structural model assessment (testing the hypothesized relationships) was used after conducting the descriptive analysis. This two-stage analytical method consisting of a measurement model and a structural model assessment is superior to a one-step assessment $[22,23]$. While the measurement model explains the measurement of each construct, the structural model defines the relationship between the variables in the structural model [21].

The use of PLS technique for both the measurement and the structural model in this research is due to its ability to perform simultaneous analysis, resulting in more precise assessments. The main reasons for choosing SEM as a statistical method for this study is that SEM offers a simultaneous analysis which leads to more accurate estimates [14-16].

\section{A. Descriptive analysis}

In table 1 , the values of mean and standard deviation are illustrated as follows: Idealized influence mean score of 3.13 out of 5.0, with a standard deviation of 1.25, indicating that the respondents agreed that leaders instill pride in others for being associated with them, go beyond self-interest for the good of the group, act in ways that build others' respect for them, and talk about their most important values and beliefs. Inspirational motivation mean score of 2.96 out of 5.0, with a standard deviation of 1.11, indicating that the respondents agreed that leaders talk optimistically about the future, talk enthusiastically about what needs to be accomplished, articulate a compelling vision of the future, and express confidence that goals will be achieved. Intellectual stimulation mean score of 2.94 out of 5.0, with a standard deviation of 1.12 , indicating that the respondents agreed that leaders re-examine critical assumptions to question whether they are appropriate, seek differing perspectives when solving problems, get others to look at problems from many different angles, and suggest new ways of looking at how to complete assignments. Individualized consideration mean score of 3.32 out of 5.0, with a standard deviation of 1.20 , indicating that the respondents agreed that leaders treat others as individuals rather than just as a member of a group, consider an individual as having different needs, abilities, and aspirations from others, seek a differing point of view when dealing with the organizational issues, and help others to develop their strengths. Learning \& growth mean score of 3.27 out of 5.0, with a standard deviation of 1.13, indicating that the respondents agreed that the organization seeks to see what is new in the business world and apply it to their work, the organization is trying to facilitate the use of new technology to take advantage of its services, the Organization Includes the growth side and motivates individuals to assess their performance, and the Organization based foundations of scientific research to solve problems, and the organization interested in developing plans and projects for the development of its business and streamline procedures. Internal process mean score of 3.10 out of 5.0, with a standard deviation of 1.17, indicating that the respondents agreed that the internal operations focus on transforming internal goals into reality, the internal operating processes focus on the quality of the services provided to the public, and Internal operations focuses on human resources, capacity development, business leadership and modern methods.

\section{B. Measurement Model Assessment}

Construct reliability and validity (consisting of convergent and discriminant validity) were utilized to test the measurement model. The individual Cronbach's alpha coefficients were examined to ascertain the reliability of each core variable in the measurement model (construct reliability). The values of all the individual Cronbach's alpha coefficients in this study were between 0.910 to 0.949, which exceeded the suggested value of 0.7 [24]. Furthermore, for testing construct reliability, the values of all the composite reliability (CR) were between 0.931 to 0.960 , which exceeded $0.7 \quad[25,26]$. Therefore, as illustrated in Table 1, construct reliability has been satisfied as Cronbach's Alpha and CR were relatively error-free for all the constructs.

Assessment of Indicator reliability was done by using factor loadings. When the associated indicators have much in 
The Relationship between Transformational Leadership and Organizational Performance: The Case of Government Sector in UAE

common, this is captured in the construct and indicated by high loadings on the construct [23]. According to Hair et al. (2010) [21], values exceeding 0.50 indicate significant factor loadings. Table 1 shows that all items in this study had factor loadings higher than the recommended value of 0.5 except for items LG7 and IP6 which was eliminated from the scale due to low loadings.
Average variance extracted (AVE) was used in this study to assess Convergent validity, which shows the degree that a measure correlates positively with alternative measures of the same construct. The values of all AVE were between 0.693 and 0.834, which exceeded the recommended value of 0.50 [23]. Therefore, all constructs have fulfilled the convergent validity satisfactorily, as illustrated in Table 1

Table 1: Mean, standard deviation, loading, cronbach's Alpha, CR and AVE

\begin{tabular}{|c|c|c|c|c|c|c|c|}
\hline Constructs & Item & $\begin{array}{l}\text { Loading } \\
(>0.5)\end{array}$ & M & $\mathrm{SD}$ & $\begin{array}{c}\alpha \\
(>0.7)\end{array}$ & $\begin{array}{c}\text { CR } \\
(>0.7)\end{array}$ & $\begin{array}{c}\text { AVE } \\
(>0.5)\end{array}$ \\
\hline \multirow{4}{*}{$\begin{array}{l}\text { Idealized } \\
\text { Influence } \\
\text { (II) }\end{array}$} & II1 & 0.920 & \multirow{4}{*}{3.13} & \multirow{4}{*}{1.25} & \multirow{4}{*}{0.934} & \multirow{4}{*}{0.953} & \multirow{4}{*}{0.834} \\
\hline & II2 & 0.917 & & & & & \\
\hline & II3 & 0.908 & & & & & \\
\hline & II4 & 0.907 & & & & & \\
\hline \multirow{4}{*}{$\begin{array}{l}\text { Inspirational } \\
\text { Motivation } \\
\text { IM) }\end{array}$} & IM1 & 0.897 & \multirow{4}{*}{2.96} & \multirow{4}{*}{1.11} & \multirow{4}{*}{0.910} & \multirow{4}{*}{0.937} & \multirow{4}{*}{0.787} \\
\hline & IM2 & 0.897 & & & & & \\
\hline & IM3 & 0.890 & & & & & \\
\hline & IM4 & 0.865 & & & & & \\
\hline \multirow{4}{*}{$\begin{array}{l}\text { Intellectual } \\
\text { Stimulation } \\
\text { (IS) }\end{array}$} & IS1 & 0.880 & \multirow{4}{*}{2.94} & \multirow{4}{*}{1.12} & \multirow{4}{*}{0.918} & \multirow{4}{*}{0.942} & \multirow{4}{*}{0.803} \\
\hline & IS2 & 0.899 & & & & & \\
\hline & IS3 & 0.912 & & & & & \\
\hline & IS4 & 0.894 & & & & & \\
\hline \multirow{4}{*}{$\begin{array}{l}\text { Individualized } \\
\text { Consideration } \\
\text { (IC) }\end{array}$} & IC1 & 0.911 & \multirow{4}{*}{3.32} & \multirow{4}{*}{1.20} & \multirow{4}{*}{0.925} & \multirow{4}{*}{0.946} & \multirow{4}{*}{0.816} \\
\hline & IC2 & 0.909 & & & & & \\
\hline & IC3 & 0.913 & & & & & \\
\hline & IC4 & 0.879 & & & & & \\
\hline \multirow{7}{*}{$\begin{array}{l}\text { Learning \& } \\
\text { Growth } \\
\text { (LG) }\end{array}$} & LG1 & 0.919 & \multirow{7}{*}{3.27} & \multirow{7}{*}{1.13} & \multirow{7}{*}{0.949} & \multirow{7}{*}{0.960} & \multirow{7}{*}{0.799} \\
\hline & LG2 & 0.913 & & & & & \\
\hline & LG3 & 0.901 & & & & & \\
\hline & LG4 & 0.906 & & & & & \\
\hline & LG5 & 0.853 & & & & & \\
\hline & LG6 & 0.868 & & & & & \\
\hline & LG7 & Deleted & & & & & \\
\hline & IP1 & 0.865 & & & & & \\
\hline & IP2 & 0.883 & & & & & \\
\hline Internal & IP3 & 0.847 & & & & & \\
\hline Process & IP4 & 0.841 & 3.10 & 1.17 & 0.910 & 0.931 & 0.693 \\
\hline (IP) & IP5 & 0.857 & & & & & \\
\hline & IP4 & Deleted & & & & & \\
\hline & IP5 & 0.686 & & & & & \\
\hline
\end{tabular}

Note: M=Mean; $\mathrm{SD}=$ Standard Deviation, $\alpha=$ Cronbach's alpha; $\mathrm{CR}=$ Composite Reliability, AVE = Average Variance Extracted.

- The measurement used is seven-point scale ranging from 1 (strongly disagree) to 5 (strongly agree). - All the factor loadings of the individual items are statistically significant (p < 0.01) except for the items LG7 and IP6 which eliminated from the scale due to low loadings.

Key: II: idealized influence, IM: inspirational motivation, IS: intellectual stimulation, IC: individualized consideration, LG: learning \& growth, IP: internal process.

The extent that items differentiate among [23]. In this study, the indicators' outer constructs or measure distinct concepts is shown loadings on a construct exceeded all its by Discriminant validity. Cross-loadings, cross-loadings with other constructs, and hence, Fornell-Larcker, and heterotrait-monotrait ratio the cross loading criterion had satisfied the (HTMT) were used to assess the discriminant validity of the measurement model. Usually, cross-loadings are used as the first step in testing discriminant validity of the indicators 
Table 2: Results of discriminant validity by the cross loading

\begin{tabular}{|c|c|c|c|c|c|c|}
\hline & II & IM & IS & IC & $\mathrm{LG}$ & IP \\
\hline II1 & 0.920 & 0.619 & 0.621 & 0.633 & 0.502 & 0.432 \\
\hline II2 & 0.917 & 0.592 & 0.627 & 0.640 & 0.494 & 0.431 \\
\hline II3 & 0.908 & 0.569 & 0.644 & 0.597 & 0.490 & 0.444 \\
\hline II4 & 0.907 & 0.598 & 0.634 & 0.657 & 0.485 & 0.458 \\
\hline IM1 & 0.603 & 0.897 & 0.577 & 0.597 & 0.457 & 0.430 \\
\hline IM2 & 0.572 & 0.897 & 0.531 & 0.567 & 0.423 & 0.400 \\
\hline IM3 & 0.566 & 0.890 & 0.545 & 0.550 & 0.431 & 0.378 \\
\hline IM4 & 0.569 & 0.865 & 0.537 & 0.537 & 0.400 & 0.379 \\
\hline IS1 & 0.602 & 0.503 & 0.880 & 0.556 & 0.462 & 0.436 \\
\hline IS2 & 0.628 & 0.569 & 0.899 & 0.660 & 0.424 & 0.456 \\
\hline IS3 & 0.640 & 0.590 & 0.912 & 0.621 & 0.465 & 0.436 \\
\hline IS4 & 0.608 & 0.552 & 0.894 & 0.618 & 0.425 & 0.427 \\
\hline IC1 & 0.628 & 0.590 & 0.637 & 0.911 & 0.480 & 0.432 \\
\hline $\mathrm{IC} 2$ & 0.608 & 0.559 & 0.628 & 0.909 & 0.435 & 0.397 \\
\hline IC3 & 0.643 & 0.582 & 0.620 & 0.913 & 0.478 & 0.359 \\
\hline IC4 & 0.620 & 0.562 & 0.584 & 0.879 & 0.439 & 0.382 \\
\hline LG1 & 0.515 & 0.463 & 0.455 & 0.473 & 0.919 & 0.323 \\
\hline LG2 & 0.482 & 0.442 & 0.447 & 0.448 & 0.913 & 0.287 \\
\hline LG3 & 0.511 & 0.442 & 0.443 & 0.484 & 0.901 & 0.330 \\
\hline LG4 & 0.464 & 0.423 & 0.446 & 0.453 & 0.906 & 0.350 \\
\hline LG5 & 0.435 & 0.410 & 0.431 & 0.434 & 0.853 & 0.339 \\
\hline LG6 & 0.485 & 0.408 & 0.436 & 0.429 & 0.868 & 0.370 \\
\hline IP1 & 0.395 & 0.393 & 0.411 & 0.366 & 0.353 & 0.865 \\
\hline IP2 & 0.396 & 0.384 & 0.408 & 0.353 & 0.337 & 0.883 \\
\hline IP3 & 0.462 & 0.399 & 0.440 & 0.393 & 0.285 & 0.847 \\
\hline IP4 & 0.406 & 0.383 & 0.411 & 0.353 & 0.307 & 0.841 \\
\hline IP5 & 0.386 & 0.341 & 0.416 & 0.374 & 0.287 & 0.857 \\
\hline IP7 & 0.372 & 0.335 & 0.360 & 0.339 & 0.292 & 0.686 \\
\hline
\end{tabular}

Key: II: idealized influence, IM: inspirational motivation, IS: intellectual stimulation, IC: individualized consideration, LG: learning \& growth, IP: internal process.

Table 3 displays the results for discriminant validity by using the Fornell-Larcker criterion. It was found that the square root of the AVEs on the diagonals (shown in bold) are greater than the correlations between constructs (corresponding row and column values), indicating strong correlation between the constructs and their respective indicators as compared to the other constructs in the model [27]. According to Hair et al.
(2017) [21], this indicates a good discriminant validity. Furthermore, the exogenous constructs have a correlation of less than 0.85 [28]. Therefore, all constructs had their discriminant validity fulfilled satisfactorily.

Table 3: Results of discriminant validity by Fornell-Larcker criterion

\begin{tabular}{l|cccccc}
\hline & Factors & 1 & 2 & 3 & 4 & 5 \\
\cline { 2 - 6 } 1 & & II & IC & IM & IS & \\
2 & II & $\mathbf{0 . 9 1 3}$ & & & & \\
3 & IC & 0.692 & $\mathbf{0 . 9 0 3}$ & & & \\
4 & IM & 0.651 & 0.635 & $\mathbf{0 . 8 8 7}$ & & \\
5 & IS & 0.691 & 0.684 & 0.618 & $\mathbf{0 . 8 9 6}$ & 0.594 \\
\hline
\end{tabular}

Note: Diagonals represent the square root of the average variance extracted while the other entries represent the correlations.

Key: II: idealized influence, IM: inspirational motivation, IS: intellectual stimulation, IC: individualized consideration, OP: organizational performance.

The Fornell-Larcker criterion has been subjected to debate. because it does not have the ability to determine precisely the lack of discriminant validity in normal research situations. Therefore, another technique has been suggested, namely the heterotrait-monotrait ratio (HTMT) of correlations based on the multitrait-multimethod matrix. HTMT has been used to test discriminant validity in this study. The discriminant validity poses certain issues when the HTMT value is higher than the $\mathrm{HTMT}_{0.90}$ value of 0.90 (Gold, Malhotra, Segar, \& Segars, 2001) or $\mathrm{HTMT}_{0.85}$ value of 0.85 
The Relationship between Transformational Leadership and Organizational Performance: The Case of Government Sector in UAE

(Kline, 2010), but Table 4 shows that all the HTMT values were less than the 0.85 , hence fulfilling the discriminant validity requirement

Table 4: Results of discriminant validity by HTMT

\begin{tabular}{l|cccccc}
\hline & Factors & 1 & 2 & 3 & 4 & 5 \\
\cline { 2 - 6 } & & II & IC & IM & IS \\
2 & II & & & \\
& IC & 0.745 & & & \\
3 & IM & 0.706 & 0.691 & & \\
4 & IS & 0.747 & 0.743 & 0.675 & \\
5 & OP & 0.671 & 0.621 & 0.616 & 0.65 \\
\hline
\end{tabular}

Key: II: idealized influence, IM: inspirational motivation, IS: intellectual stimulation, IC: individualized consideration, OP: organizational performance.

\section{Structural Model Assessment}

The structural model can be tested by computing beta $(\beta)$, $\mathrm{R}^{2}$, and the corresponding t-values via a bootstrapping procedure with a resample of 5,000 [21]. They also suggested looking at the effect sizes $\left(\mathrm{f}^{2}\right)$ and the predictive relevance $\left(\mathrm{Q}^{2}\right)$. While $\mathrm{p}$-value ascertains the existence of the effect, the effect size is not shown (Sullivan \& Feinn; 2012).

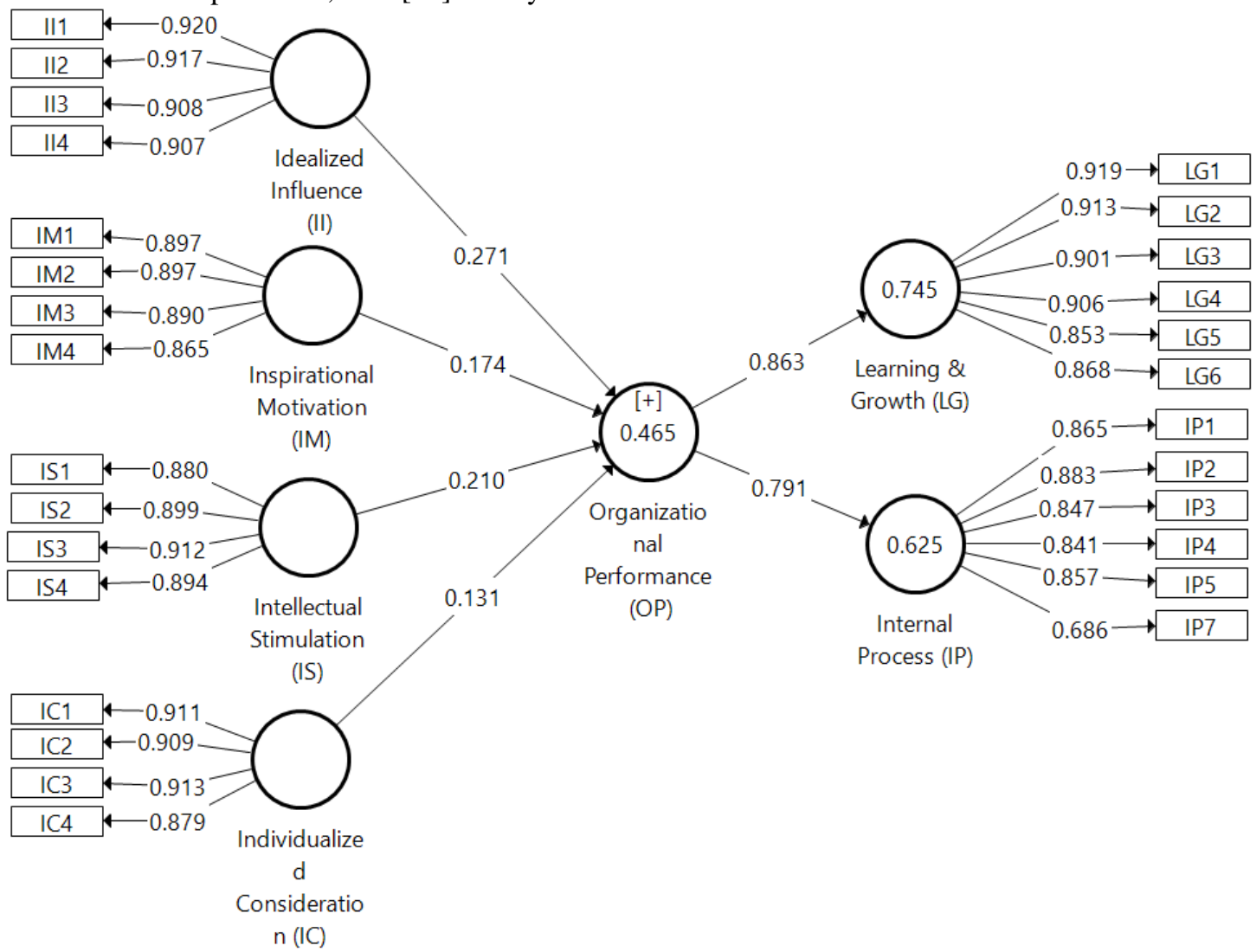

Key: II: idealized influence, IM: inspirational motivation, IS: intellectual stimulation, IC: individualized consideration, OP: organizational performance, LG: learning \& growth, IP: internal process.

Fig. 2: PLS algorithm results

\section{a. Hypotheses Tests}

Figure 2 and Table 5 depict the structural model assessment, showing the results of the hypothesis tests, with 4 out of the 4 hypotheses are supported. Idealized influence, inspirational motivation, intellectual stimulation, and individualized consideration significantly predict organizational performance. Hence, H1, $\mathrm{H} 2, \quad \mathrm{H} 3$ and $\mathrm{H} 4$ are accepted with $(\beta=0.271, \mathrm{t}=4.399, \mathrm{p} \quad<0.001)$, $(\beta=0.174, \mathrm{t}=2.953, \mathrm{p}$ $<0.001)$, $(\beta=0.210, \mathrm{t}=3.477, \mathrm{p} \quad<0.01), \quad$ and $(\beta=0.131, \mathrm{t}=1.989, \mathrm{p}<0.05) \quad$ respectively.
The strength of the relationship between exogenous and endogenous constructs are measured by the standardized path coefficients, which in this case show that the direct effects of idealized influence on organizational performance is much stronger than the influence of other variables.

Forty-seven percent of the variance in organizational performance is explained by idealized influence, inspirational motivation, intellectual stimulation, and individualized consideration. 
values of $\mathrm{R}^{2}$ have an acceptable level of explanatory power, indicating a substantial model [29].

In assessing the predictive relevance of the proposed research model, this study had applied the blindfolding procedure. This procedure should be employed on endogenous constructs with a reflective measurement only [21]. According to Hair et al. (2017) [21], a particular endogenous construct of the proposed model has predictive relevance if the value of $\mathrm{Q}^{2}$ exceeded 0 . In this study, The $\mathrm{Q}^{2}$ value was greater than 0 , and hence, it can be concluded that the proposed model has an adequate predictive relevance (refer to Table 5). A relative measure of predictive relevance is indicated by $\mathrm{Q}^{2}$ values of 0.35 for large, 0.15 for medium, and 0.02 for small. The exogenous construct in this study was found to have medium predictive relevance.
The existence of multicollinearity poses a problem as it indicates overlapping of the variance that the exogenous constructs explain in the endogenous construct. Therefore, it cannot justify each variance in the endogenous variable. Variance inflation factor (VIF) is commonly used as a measurement of the degree of multicollinearity. A value exceeding 10 for the largest VIF indicates a problem. Meanwhile, Hair et al. (2017) [21] suggested that a value exceeding 5 for the largest VIF indicates a multicollinearity problem. The VIF values in this study are between 2.039 and 2.520 (i.e. less than 5), and hence, there is no significant multicollinearity issue among the exogenous constructs. In other words, there is no overlapping of the variance that the exogenous constructs explained in the endogenous construct

Table 5: Structural path analysis result

\begin{tabular}{clcccccccc}
\hline \hline \multirow{2}{*}{ Hypothesis } & \multirow{2}{*}{ Relationship } & $\begin{array}{c}\text { Std } \\
\text { Beta }\end{array}$ & Std Error & t-value & p-value & Decision & $\mathrm{R}^{2}$ & $\mathrm{Q}^{2}$ & VIF \\
\hline H1 & II $\rightarrow$ OP & 0.271 & 0.062 & 4.399 & 0.000 & Supported & 0.47 & 0.217 & 2.520 \\
H2 & IM $\rightarrow$ OP & 0.174 & 0.059 & 2.953 & 0.002 & Supported & & & 2.039 \\
H3 & IS $\rightarrow$ OP & 0.210 & 0.060 & 3.477 & 0.000 & Supported & & 2.363 \\
H4 & IC $\rightarrow$ OP & 0.131 & 0.066 & 1.989 & 0.023 & Supported & & 2.421 \\
\hline \hline
\end{tabular}

Key: II: idealized influence, IM: inspirational motivation, IS: intellectual stimulation, IC: individualized consideration, OP: organizational performance

\section{b. Importance-Performance Map Analysis (IPMA)}

Importance-performance matrix analysis (IPMA) was employed as a post-doc PLS procedure in this study, with the organizational performance used as the outcome construct. According to Hair et al. (2017) [21], the IPMA provides an estimation of the total effects corresponding to the importance of predecessor constructs in affecting the target construct (organizational performance); the average latent variable scores correspond to their performance, whereas the index values' (performance scores) calculation was achieved by rescaling the scores of the latent constructs to within a range from 0 (lowest performance) to 100 (highest performance). IPMA enhances the results of PLS analysis [30] because it gives attention to the latent constructs' average value as well as their indicators (the performance dimension) in addition to performing the path coefficients analysis (the importance dimension). The results for total effects (importance) and index values (performance) of the IPMA of the outcome construct organizational performance is displayed in Tables 6 .

Table 6: IPMA for Organizational performance

\begin{tabular}{lcc}
\hline \multicolumn{1}{c}{ Latent constructs } & $\begin{array}{c}\text { Total effect of the construct } \\
\text { Organizational performance (Importance) }\end{array}$ & $\begin{array}{c}\text { Index values } \\
\text { (Performance) }\end{array}$ \\
\hline Idealized Influence (II) & 0.207 & 53.27 \\
Inspirational Motivation (IM) & 0.154 & 49.13 \\
Intellectual Stimulation (IS) & 0.185 & 48.49 \\
Individualized Consideration (IC) & 0.105 & 57.92 \\
\hline
\end{tabular}

Note: TL: transformational leadership, LG: learning \& growth, IP: internal process, PD: power distance

The scores for total effects and index values were plotted importance value compared to other constructs in the on a priority map (refer to Figure 3). It can be observed that proposed model idealized influence is a very important factor in determining the organizational performance due to its relatively higher 
While there exists an apparent gap on the importance of factors for determining organizational performance, these factors have similar performance. IPMA aims to identify the predecessors that have both relatively high importance (with strong total effect) and relatively low performance for the target construct (with low average latent variable scores)
[21]. Particular attention may be given to the attributes of these constructs, which can be potential areas for improvement. In sum, in order to improve the organizational performance, the managerial activities should focus on enhancing the performance of idealized influence and intellectual stimulation.

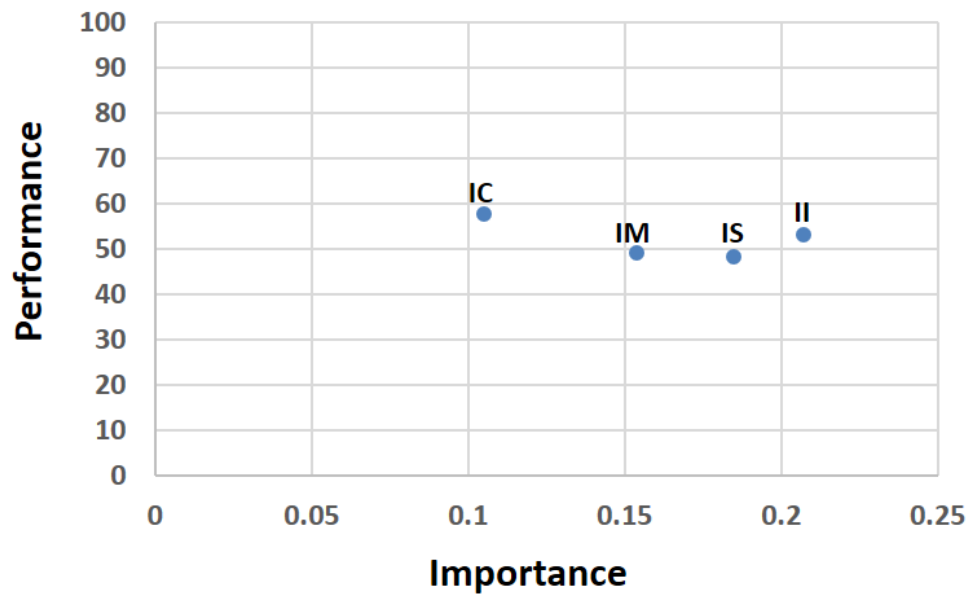

Key: : II: idealized influence, IM: inspirational motivation, IS: intellectual stimulation, IC: individualized consideration Fig. 3: IPMA (Priority Map) for organizational performance

\section{DISCUSSION}

Based on the proposed model, this study improves the understanding of the role played by the characteristics of transformational leadership in terms of Idealized influence, Inspirational motivation, Intellectual stimulation, and Individualized consideration in predicting organizational performance in terms of learning \& growth, and internal processes among employees in government sector in the United Arab Emirates, and highlights relevant implications. The discussions are further detailed in the following.

The study found that idealized influence positively affects organizational performance among employees in government sector in the United Arab Emirates, this is supported by previous studies [8]. It is explained by the fact that the more government organization leaders give the sense of pride to their subordinates, always put their group before self-interest, act in a way that is being admired, and talking about most important values and beliefs, the more organizations are seeking new business practices, utilize new technologies and scientific research to solve problems, focus more on human resource development. Besides, internal operations are focusing on fulfilling their internal goals, and on the quality of the services to the public, and develop channels of communication to facilitate the transfer of information.
Likewise, it was found that Inspirational Motivation positively affects organizational performance among employees in government sector in the United Arab Emirates, this is supported by previous studies. It is explained by the fact that the more leaders spread the sense of optimism of the future, and being more enthusiastic about what needs to be accomplished, lay out a vision of the future, and being confident of achieving organizations goals, the more organizations are seeking new business practices, utilize new technologies and scientific research to solve problems, focus more on human resource development. Besides, internal operations are focusing on fulfilling their internal goals, and on the quality of the services to the public, and develop channels of communication to facilitate the transfer of information $[15,30]$.

Additionally, Intellectual Stimulation was found to positively organizational performance of organizations among employees in government sector in the United Arab Emirates, this is supported by previous studies. It is explained by the fact that the more leaders tend to re-examine critical assumptions, look for multiple perspectives on problem-solving, and offer new options on how assignment to be completed, the more organizations are seeking new business practices, utilize new technologies and scientific research to solve problems, focus more on human resource development. Besides, internal operations are 
focusing on fulfilling their internal goals, and on the quality of the services to the public, and develop channels of communication to facilitate the transfer of information.

Finally, the study found that individualized consideration significantly influences organizational performance, this is supported by previous studies. It is explained by the fact that The more leaders treat others as individuals rather than just as a member of a group, consider an individual as having different needs, abilities, and aspirations, seek a differing point of view when dealing with the organizational issues, and help others to develop their strengths, the more organizations are seeking new business practices, utilize new technologies and scientific research to solve problems, focus more on human resource development. Besides, internal operations are focusing on fulfilling their internal goals, and on the quality of the services to the public, and develop channels of communication to facilitate the transfer of information

\section{IMPLICATIONS, LIMITATIONS AND FUTURE DIRECTIONS}

The concept of transformational leadership is a newly emerging concept, and until now, it is not fully understood by most organizations in the UAE or the Arab world. This study represents a major foundation in elevating this concept within the Emirates public sector. Therefore, this study has provided a comprehensive illustration of how the role of internal leadership practices relates to individuals, groups, and organization performance and how it can be used in the best way to enhance overall performance.

The government can benefit from the results as a guide to provide resources for informal groupings to encourage group members to generate new ideas, and to spread trust amongst the group members by strengthening the interactions within the social network to facilitate co-operation and knowledge transfer. These are key requirements for better performance. Moreover, the government should manage a knowledge source of valuable acquired knowledge to generate new ideas, to improve processes and organizational routines and adopt a developmental culture. It is vital to recruit and retain employees who have good skills, a high education level, and the competence to generate and apply new ideas.

One limitation of this study is its population selection and future researchers could validate the model in more public sectors in the UAE, as well as different Arab countries. Besides, this study focused in the public sector and did not cover the private.

This study examined only a few variables to predict organizational productivity, future research may include more variables to our model. For instance reward and recognition, job satisfaction and so forth. Can also be taken into account for future research. A comparative study among the employees of government different authorities is also suggested. Finally, the relationships proposed in this study could be tested using moderators such as gender or departments $[12$, 17].

\section{CONCLUSION}

Key conclusions are offered in the scope of the objectives of the study. The first objective sought to determine factors that influence organizational performance in terms of the learning \& growth, and internal process in the government sector in the United Arab Emirates. Regardless of various constraints to the study, the results have been encouraging, as it has managed to throw some lights on a new perspective. This study proposed a model which include transformational leadership (idealized influence, inspirational motivation, intellectual stimulation, and individualized consideration) as independent variables and organizational performance as second-order construct to learning \& growth, and internal process as the dependent variable. The results revealed that all four hypotheses are significant. The independent variables significantly explain $46.5 \%$ of organizational performance. The implications of this study have been deliberated, some directions for future research have been suggested.

APPENDIX

Appendix A

Instrument for varibles

\begin{tabular}{c|lc}
\hline Varible & \multicolumn{1}{c}{ Measure } & Source \\
\hline $\begin{array}{c}\text { Idealized } \\
\text { Influence } \\
\text { (II) }\end{array}$ & $\begin{array}{l}\text { II1: Leaders instill pride in others for being associated with them. } \\
\text { II2: Leaders go beyond self-interest for the good of the group. } \\
\end{array}$ & $\begin{array}{l}\text { II3: Leaders act in ways that build others' respect for them. } \\
\text { II4: Leaders talk about their most important values and beliefs. }\end{array}$ \\
\hline
\end{tabular}


Inspirational $\quad$ IM1: Leaders talk optimistically about the future.

Motivation IM2: Leaders talk enthusiastically about what needs to be accomplished.

(IM) IM3: Leaders articulate a compelling vision of the future.

IM4: Leaders express confidence that goals will be achieved.

Intellectual IS1: Leaders re-examine critical assumptions to question whether they are appropriate.

Stimulation $\quad$ IS2: Leaders seek differing perspectives when solving problems.

(IS)

IS3: Leaders get others to look at problems from many different angles.

IS4: Leaders suggest new ways of looking at how to complete assignments.

Individualize IC1: Leaders treat others as individuals rather than just as a member of a group.

d IC2: Leaders consider an individual as having different needs, abilities, and aspirations

Consideration from others.

(IC) IC3: Leaders seek a differing point of view when dealing with the organizational issues.

IC4: Leaders help others to develop their strengths.

Learning and LG1: Organization seeks to see what is new in the business world and apply it to their Growth work.

(LG) LG2: The Organization is trying to facilitate the use of new technology to take advantage of its services.

LG3: The Organization based foundations of scientific research to solve problems.

LG4: The Organization focuses on human resource development and performance.

LG5: Organization Includes the growth side and motivates individuals to assess their performance.

LG6: The Organization interested in developing plans and projects for the development of its business and streamline procedures.

LG7: The Organization concerned with comparative references outstanding performance measurement.

Internal IP1: The internal operations focuses on transforming internal goals into reality.

Process IP2: Satisfactory performance of the Organization is due to top management decisions

(IP) and their applications.

IP3: The internal operating processes focus on the quality of the services provided to the public.

IP4: The internal operating processes focus on human resources and capacity

development.

IP5: Internal operations focuses on business leadership and modern methods.

IP6: Internal operating processes established the organizational structure and describe the Organization's functions.

IP7: Internal operations develop channels of communication to facilitate the transfer of information.

\section{REFERENCES}

1. Avolio, B. J., Bass, B. M., \& Jung, D. I. (1999). Re-examining the components of transformational and transactional leadership using the Multifactor Leadership Questionnaire. Journal of Occupational and Organizational Psychology, 72(4), 441-462.

2. A. Ameen, \& K. Ahmad, (2011). The Role of Finance Information Systems in anti-financial corruptions: A theoretical review. In 11 International Conference on Research and Innovation in Information Systems (ICRIIS'11 (pp. 267-272).

3. A. Ameen \& K. Ahmad, (2012). Towards Harnessing Financial Information Systems in Reducing Corruption : A Review of Strategies. Australian Journal of Basic and Applied Sciences, 6(8), pp. 500-509.

4. A. Ameen, \& K. Ahmad, (2013). A Conceptual Framework of Financial Information Systems to reduce corruption. Journal of Theoretical and Applied Information Technology, 54(1), pp. 59-72.

5. A. S. Alkhateri, A. E. Abuelhassan, G. S. A. Khalifa, M. Nusari \& A. Ameen, (2018). The Impact of perceived supervisor support on employees turnover intention : The Mediating role of job satisfaction and affective organizational commitment. International Business Management, 12(7), pp. 477-492.

6. A. Ameen, H. Almari, \& O. Isaac, (2019). Determining Underlying Factors that Influence Online Social Network Usage Among Public Sector Employees in the UAE. In Fathey M. Faisal Saeed, Nadhmi Gazem (Ed.), Recent Trends in Data Science and Soft Computing. IRICT 2018. Advances in Intelligent Systems and Computing Recent Tre,843, pp. 945-954. Springer Nature Switzerland AG: Springer International Publishing.

7. Haddad, A., Ameen, A., \& Mukred, M. (2018). The Impact of Intention of Use on the Success of Big Data Adoption Via Organization Readiness
Factor. International Journal of Management and Human Science (IJMHS), 2(1), 43-51.

8. Heffernan , M., Harney, B., Cafferkey, K. and Dundon, T. (2016), "Exploring the HRM-performance relationship: the role of creativity climate and strategy", Employee Relations, Vol. 38 No. 3, pp. 438-462.

9. Turkyilmaz, A., Akman, G., Ozkan, C. and Pastuszak, Z. (2011), "Empirical study of public sector employee loyalty and satisfaction", Industrial Management \& Data Systems, Vol. 111 No. 5, pp. 675-696.

10. Kaplan, R. and Norton, D. (1996), "strategic learning \& the balanced scorecard", Strategy \& Leadership, Vol. 24 No. 5, pp. 18-24.

11. Y.-S. Wang, H.-H. Lin \& P. Luarn, (2006). Predicting consumer intention to use mobile service. Information Systems Journal, 16(2), pp. 157-179.

12. A. F. Baharuden, O. Isaac \& A. Ameen, (2019). Factors Influencing Big Data \& Analytics (BD\&A) Learning Intentions with Transformational Leadership as Moderator Variable: Malaysian SME Perspective. International Journal of Management and Human Science (IJMHS), 3(1), pp. 10-20.

13. P. Marylin, A. Ghosh, O. Isaac, S. J. V. Aravinth, \& A. Ameen, (2019). The Impact of Emotional Intelligence on Work Life Balance among Pharmacy Professionals in Malaysia. International Journal of Management and Human Science (IJMHS), 3(1), pp. 29-34.

14. O. Isaac, Z. Abdullah, T. Ramayah \& M. Mutahar Ahmed, (2017). Examining the Relationship Between Overall Quality, User Satisfaction and Internet Usage: An Integrated Individual, Technological, Organizational and Social Perspective. Asian Journal of Information Technology, 16(1), pp. 100-124. 
15. O. Isaac, Z. Abdullah, T. Ramayah \& A. M. Mutahar, (2017). Internet usage, user satisfaction, task-technology fit, and performance impact among public sector employees in Yemen. The International Journal of Information and Learning Technology, 34(3), pp. 210-241.

16. O. Isaac, Z. Abdullah, T. Ramayah, A. M. Mutahar, \& I. Alrajawy, (2017). Towards a Better Understanding of Internet Technology Usage by Yemeni Employees in the Public Sector: An Extension of the Task-Technology Fit (TTF) Model. Research Journal of Applied Sciences, 12(2), pp. 205-223.

17. B. G. Tabachnick \& L. S. Fidell, (2007). Using Multivariate Statistics. PsycCRITIQUES, 28, pp. 980.

18. R. V Krejcie, \& D. W. Morgan, (1970). Determining sample size for research activities. Educational and Psychological Measurement, 38, pp. 607-610.

19. C. M. Ringle, S. Wende \& J.-M. Becker, (2015). SmartPLS 3. Bonningstedt: SmartPLS.

20. J. C. Anderson \& D. W. Gerbing, (1988). Structural Equation Modeling in Practice: A Review and Recommended Two-Step Approach. Psychological Bulletin, 103(3), pp. 411-423.

21. J. F. J. Hair, G. T. M. Hult, C. Ringle, \& M. Sarstedt, A Primer on Partial Least Squares Structural Equation Modeling (PLS-SEM), 46 Long Range Planning 328 (2014). London: Thousand Oaks: SAGE.

22. R. E. Schumacker \& R. G. Lomax, (2004). A Beginner's Guide to Structural Equation Modeling. New York: Lawrence Erlbaum.

23. J. F. Hair, W. C. Black, B. J. Babin, \& R. E. Anderson, (2010). Multivariate Data Analysis. New Jersey.

24. V. R. Kannana \& K. C. Tan, (2005). Just in time, total quality management, and supply chain management: understanding their linkages and impact on business performance. Omega: The International Journal of Management Science, 33(2), pp. 153-162.

25. C. E. Werts, R. L. Linn, \& K. G. Jöreskog, (1974). Intraclass reliability estimates: Testing structural assumptions. Educational and Psychological Measurement, 34(1), pp. 25-33.

26. R. B. Kline, (2010). Principles and practice of structural equation modeling (3rd ed.). New York: The Guilford Press.

27. C. Fornell, \& D. F. Larcker, (1981). Evaluating structural equation models with unobservable variables and measurement error. Journal of Marketing Research, 18(1), pp. 39-50.

28. Z. Awang, (2014). Structural Equation Modeling Using AMOS. Shah Alam.Malaysia: University Teknologi MARA Publication Center.

29. J. Cohen, (1988). Statistical Power Analysis for the Behavioral Sciences (2nd Editio). LawreAssociatesnce Erlbaum.

30. C. M. Ringle \& M. Sarstedt, (2016). Gain more insight from your PLS-SEM results: The importance-performance map analysis. Industrial Management \& Data Systems, 116(9), pp. 1865-1886. 